\title{
Selective dorsal rhizotomy: an illustrated review of operative techniques
}

\author{
Nebras M. Warsi, MD, CM, ${ }^{1,2}$ Jignesh Tailor, FRCS(SN), PhD, ${ }^{2}$ lan C. Coulter, FRCS(SN), MSc, ${ }^{2}$ \\ Husain Shakil, MD, MSc, ${ }^{1}$ Adriana Workewych, BSc, ${ }^{3}$ Renée Haldenby, MSc(PT), ${ }^{4}$ \\ Sara Breitbart, MSc, ${ }^{2}$ Samuel Strantzas, MSc, ${ }^{2}$ Michael Vandenberk, MSc, ${ }^{2}$ \\ Michael C. Dewan, MD, MSCl, ${ }^{2}$ and George M. Ibrahim, MD, PhD ${ }^{1,2}$
}

\begin{abstract}
1 Division of Neurosurgery, Department of Surgery, University of Toronto; ${ }^{2}$ Division of Neurosurgery, Hospital for Sick Children; ${ }^{3}$ Faculty of Medicine and ${ }^{4}$ Department of Pediatrics, University of Toronto, Ontario, Canada
\end{abstract}

OBJECTIVE Selective dorsal rhizotomy (SDR) is a procedure primarily performed to improve function in a subset of children with limitations related to spasticity. There is substantial variability in operative techniques among centers and surgeons. Here, the authors provide a technical review of operative approaches for SDR.

METHODS Ovid MEDLINE, Embase, and PubMed databases were queried in accordance with PRISMA guidelines. All studies included described a novel surgical technique. The technical nuances of each approach were extracted, including extent of exposure, bone removal, and selection of appropriate nerve roots. The operative approach preferred at the authors' institution (the " $2 \times 3$ exposure") is also detailed.

RESULTS Five full-text papers were identified from a total of 380 articles. Operative approaches to SDR varied significantly with regard to level of exposure, extent of laminectomy, and identification of nerve roots. The largest exposure involved a multilevel laminectomy, while the smallest exposure involved a keyhole interlaminar approach. At the Hospital for Sick Children, the authors utilize a two-level laminoplasty at the level of the conus medullaris. The benefits and disadvantages of the spectrum of techniques are discussed, and illustrative figures are provided.

CONCLUSIONS Surgical approaches to SDR vary considerably and are detailed and illustrated in this review as a guide for neurosurgeons. Future studies should address the long-term impact of these techniques on functional outcomes and complications such as spinal deformity.

https://thejns.org/doi/abs/10.3171/2019.12.PEDS19629

KEYWORDS selective dorsal rhizotomy; cerebral palsy; spasticity; spine

S ELECTIVE dorsal rhizotomy (SDR) is a neurosurgical treatment primarily for a subset of children with cerebral palsy (CP) characterized by spastic diplegia. Dorsal rhizotomy was originally practiced in the late 19th century for the relief of intractable pain by Abbe, Bennett, and Dana. ${ }^{5}$ After Sherrington demonstrated that sectioning dorsal roots could reduce tone in an affected limb, dorsal rhizotomy was adopted for the treatment of spasticity rather than pain. ${ }^{5}$ These early procedures carried substantial morbidity, primarily related to severe sensory loss, bladder denervation, postoperative weakness, and persistence of spasticity. ${ }^{23}$

In the 1970s dorsal rhizotomy started to become more "selective." In Montpellier, France, Gros introduced intraoperative electromyography (EMG) to determine the cor- respondence of each nerve root to specific muscle groups; those that contributed the most to spasticity were cut, while rootlets thought to contribute to gait and postural control were spared., ${ }^{5,23}$ The procedure also became multidisciplinary, with physical therapy and electrophysiology working alongside the surgical team. In parallel, Fasano et al. described the electrophysiological characteristics of rootlets thought most likely to contribute to abnormal muscular tone. ${ }^{6} \mathrm{He}$ advocated for sectioning nerve roots that had abnormal stimulation thresholds and spread activity to muscles not normally innervated by that spinal level. ${ }^{6}$ Following his 1987 description of the procedure, Peacock is credited with popularizing SDR by expanding upon these previous advances. ${ }^{17}$

Today, SDR is experiencing a resurgence in popularity

ABBREVIATIONS CP = cerebral palsy; EMG = electromyography; $S D R$ = selective dorsal rhizotomy.

SUBMITTED October 20, 2019. ACCEPTED December 6, 2019.

INCLUDE WHEN CITING Published online February 7, 2020; DOI: 10.3171/2019.12.PEDS19629. 
TABLE 1. Summary of operative techniques

\begin{tabular}{|c|c|c|c|}
\hline Authors \& Year & Level of Exposure & Extent of Bony Exposure & Nerve Root Identification \\
\hline Peacock et al., 1987 & L2-5 & Multilevel laminectomy/laminoplasty & Simple anatomical/EMG \\
\hline Park \& Johnston, 2006 & $\begin{array}{l}\text { Level of conus (determined on } \\
\text { ultrasound) }\end{array}$ & Single-level laminectomy & $\begin{array}{l}\text { Anatomical/EMG w/ operating microscope; identify } \\
\text { cleft at conus }\end{array}$ \\
\hline Bales et al., 2016 & $\begin{array}{l}\text { Below conus (determined on } \\
\text { MRI) }\end{array}$ & Single-level laminectomy & $\begin{array}{l}\text { EMG thresholds used to separate dorsal \& ventral } \\
\text { roots }\end{array}$ \\
\hline $\begin{array}{l}\text { Sindou \& Georgoulis, } \\
2015\end{array}$ & $\begin{array}{l}2 \text { to } 3 \text { levels of interest (most } \\
\text { affected nerve roots) }\end{array}$ & $\begin{array}{l}\text { 2- to 3-level interlaminar keyhole } \\
\text { approach }\end{array}$ & $\begin{array}{l}\text { Anatomical/EMG based on the position w/in neural } \\
\text { foramen }\end{array}$ \\
\hline Funk \& Haberl, 2016 & $\begin{array}{l}\text { Level of conus (determined on } \\
\text { MRI) }\end{array}$ & Single-level laminoplasty & $\begin{array}{l}\text { Anatomical/EMG w/ operating microscope; cleft at } \\
\text { conus identified }\end{array}$ \\
\hline $\begin{array}{l}\text { Current technique }(2 \times 3 \\
\quad \text { exposure })\end{array}$ & $\begin{array}{l}\text { Level of conus (determined on } \\
\text { MRI) }\end{array}$ & 2-level laminoplasty & $\begin{array}{l}\text { Anatomical/EMG w/ operating microscope; cleft at } \\
\text { conus identified }\end{array}$ \\
\hline
\end{tabular}

among neurosurgeons, patients, and healthcare networks. The rise of social media has strengthened patient and family interest in the procedure, while health-economic analyses have demonstrated its cost-effectiveness. ${ }^{2,15}$ In 2014 the National Health Service in England commissioned a prospective study across five hospitals to revaluate the state of funding for the procedure, leading to its recognition and funding from 2018 onwards. ${ }^{26}$ However, despite this growth in popularity, multiple variations in the procedure have been described with respect to location of exposure, extent of bone removal, and the identification and selection of most appropriate roots for sectioning. The present study aims to serve as a technical review of published methods for SDR. To this end, we conducted a systematic review of all described surgical approaches to SDR assessing their technical nuances, benefits, and potential limitations. We conclude by describing modifications of the procedure at Toronto's Hospital for Sick Children.

\section{Methods \\ Study Selection}

The search protocol was developed according to the PRISMA guidelines (see Supplementary Fig. 1 for full search strategy and Supplementary Fig. 2 for PRISMA checklist). ${ }^{13}$ Briefly, a literature search was performed on August 20, 2019, using the keywords "cerebral palsy," "rhizotomy," and/or "selective dorsal rhizotomy" in combination. The databases searched included Ovid MEDLINE, Embase, and PubMed with no search restrictions. Title, abstract, and full-text review were conducted by two independent authors (N.M.W., M.C.D.). Disagreements were resolved with discussion and re-review. All final studies included described a novel surgical technique not previously published.

\section{Data Synthesis}

Data pertaining to operative technique-with a particular emphasis on the extent of exposure, bony removal, and selection of appropriate nerve roots-were extracted for each study and are summarized in Table 1. Surgical illustrations were created for each approach by a professional illustrator (A.W.).

\section{Results}

A total of 380 manuscripts were identified by our initial search (Supplementary Fig. 1). Overall, 343 studies were excluded following title and abstract review. Of the 37 fulltext articles that were assessed, 14 reviews were excluded, 11 were nontechnical papers, 3 were repeat descriptions of previously published techniques, 2 were conference papers, and 2 were in a foreign language. The remaining 5 articles consisted of original work written in English and describing a unique operative approach to SDR. These findings are summarized in Table 1 and detailed graphically in Fig. 1.

\section{Peacock et al.}

In the early 1980s, Peacock and Eastman pioneered a form of SDR for children with spasticity secondary to $\mathrm{CP}$, which involved rhizotomies performed in the cauda equina rather than the conus. ${ }^{18}$ This technique was later described in greater detail, coinciding with the reemergence of SDR for the treatment of CP-associated lowerlimb spasticity in the modern era. ${ }^{17}$

Under general anesthesia, patients are positioned prone and a midline incision is made to expose the lumbar vertebrae. Partial L2-5 laminectomies are undertaken with adjacent facet joint preservation. Following a longitudinal dural opening and arachnoid dissection, the posterior roots of L2-S1 are identified and isolated. Utilizing two unipolar probes, rootlets of each posterior root are sequentially subjected to electrical stimulation via single and tetanic stimuli in the range of $10-150 \mathrm{~V}$, as described by Fasano et al. ${ }^{6,7}$ The corresponding muscle responses were observed both visually and with EMG.

Criteria that support the decision to divide the rootlet/s of interest include a low threshold associated with a sustained muscular contraction or spread of contraction to contiguous muscle groups beyond the rootlet's segmental distribution. Conversely, rootlets are left intact if thresholds are relatively high and muscle contraction is brief without diffusion.

\section{Park and Johnston}

In 2006, Park and Johnston ${ }^{16}$ subsequently reported 


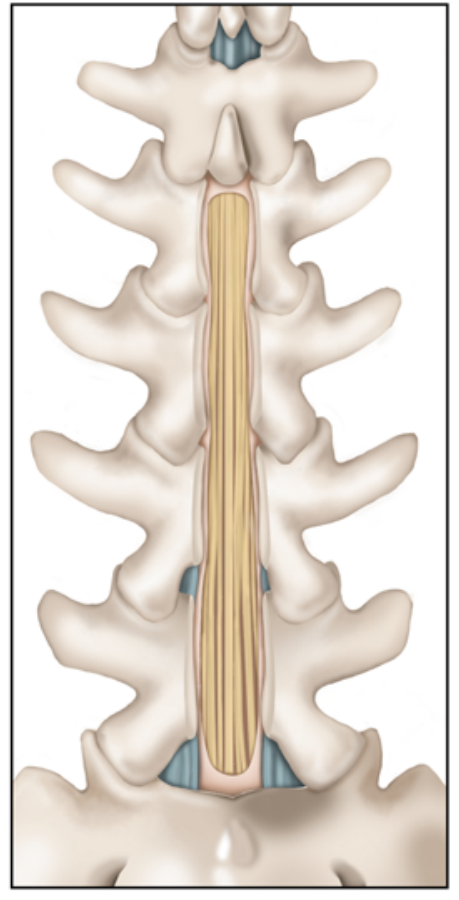

Peacock et al. 1987

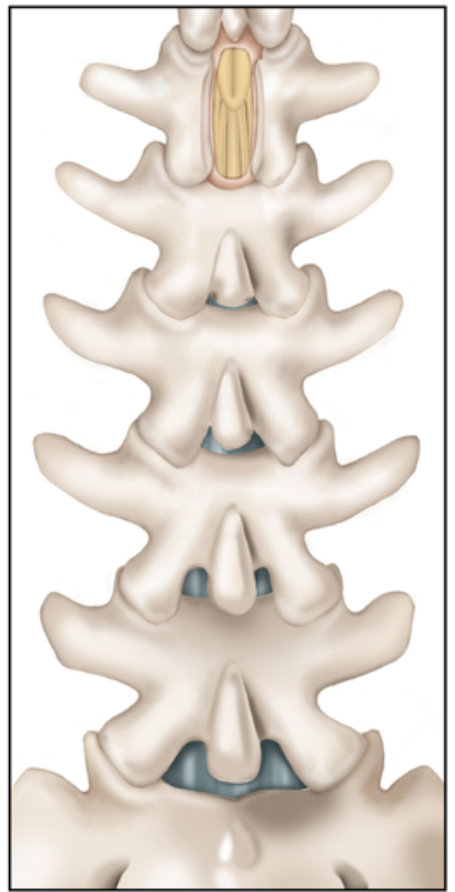

Funk \& Haberl 2016

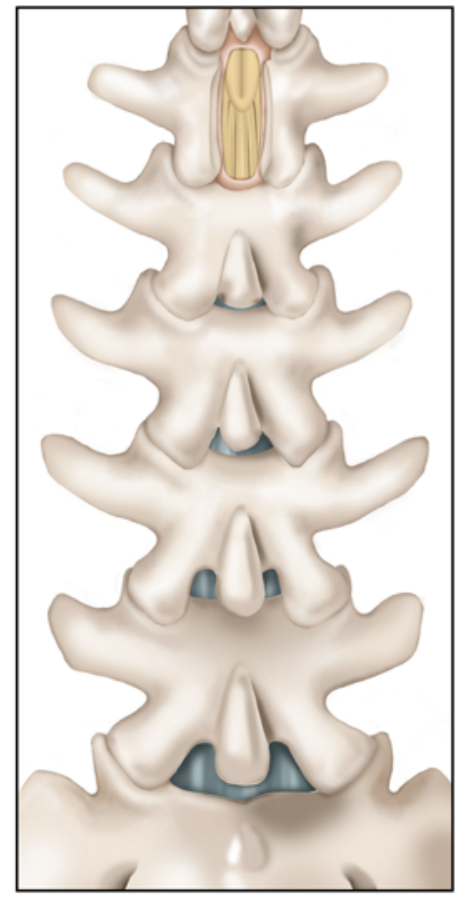

Park \& Johnston 2006

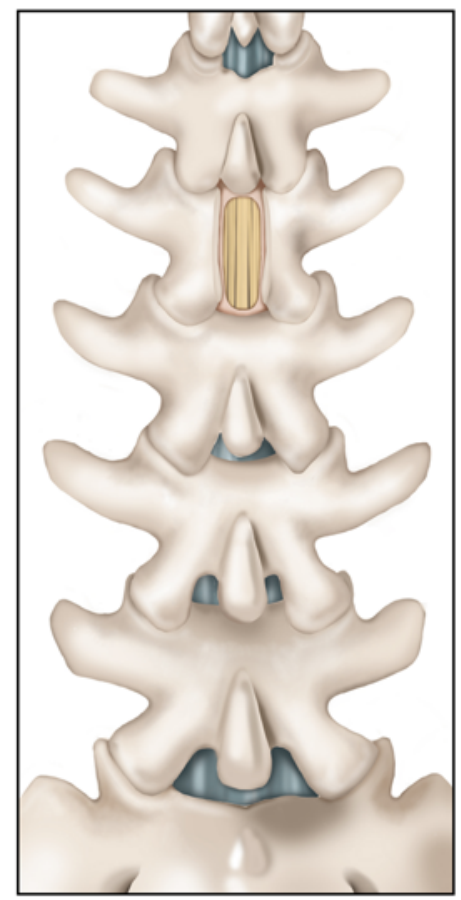

Bales et al. 2016

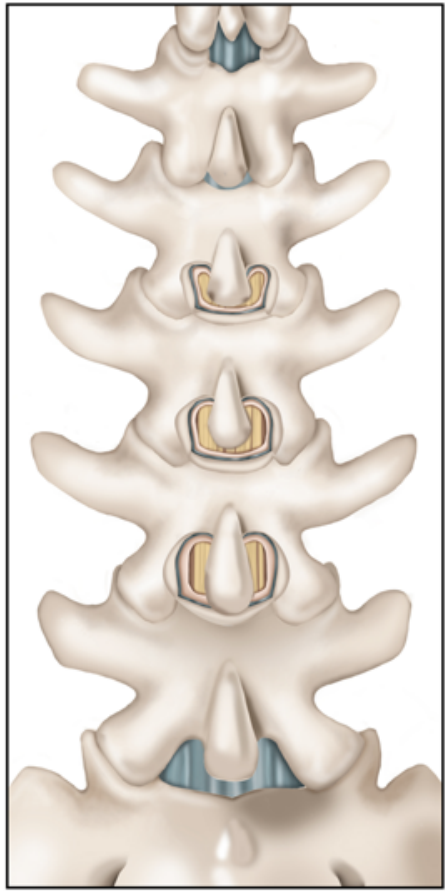

Sindou \& Georgoulis 2015

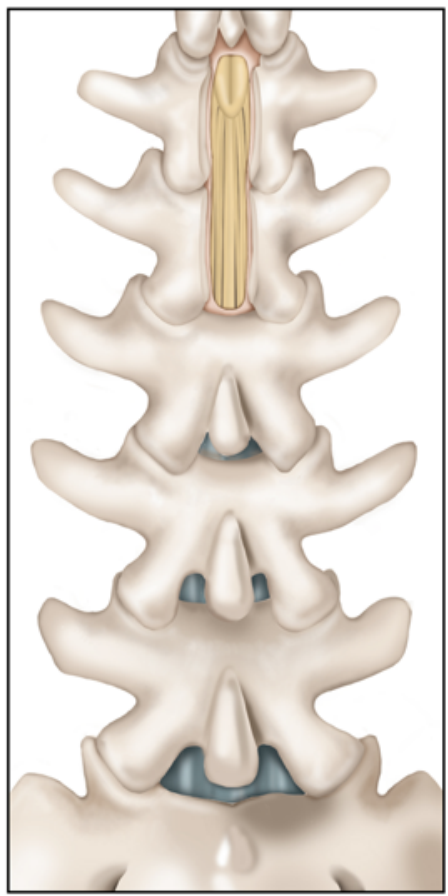

Current approach

FIG. 1. Illustrations of the different bony exposures in SDR. Peacock and colleagues' 1987 technique ${ }^{17}$ utilized a multilevel laminectomy below the conus; in 2006, Park and Johnston ${ }^{16}$ modified this to a single-level laminectomy at the conus; Sindou and Georgoulis ${ }^{22}$ used a less-invasive but more challenging keyhole interlaminar exposure; in 2016, Funk and Haberl ${ }^{8}$ described a single-level laminoplasty at the conus; that same year, Bales et al. modified Park's exposure to a single-level laminectomy below the conus, with EMG to identify relevant nerve roots; and finally, our so-called $2 \times 3$ approach is based on a two-level laminoplasty at the level of the conus. Copyright Nebras Warsi. Published with permission. 

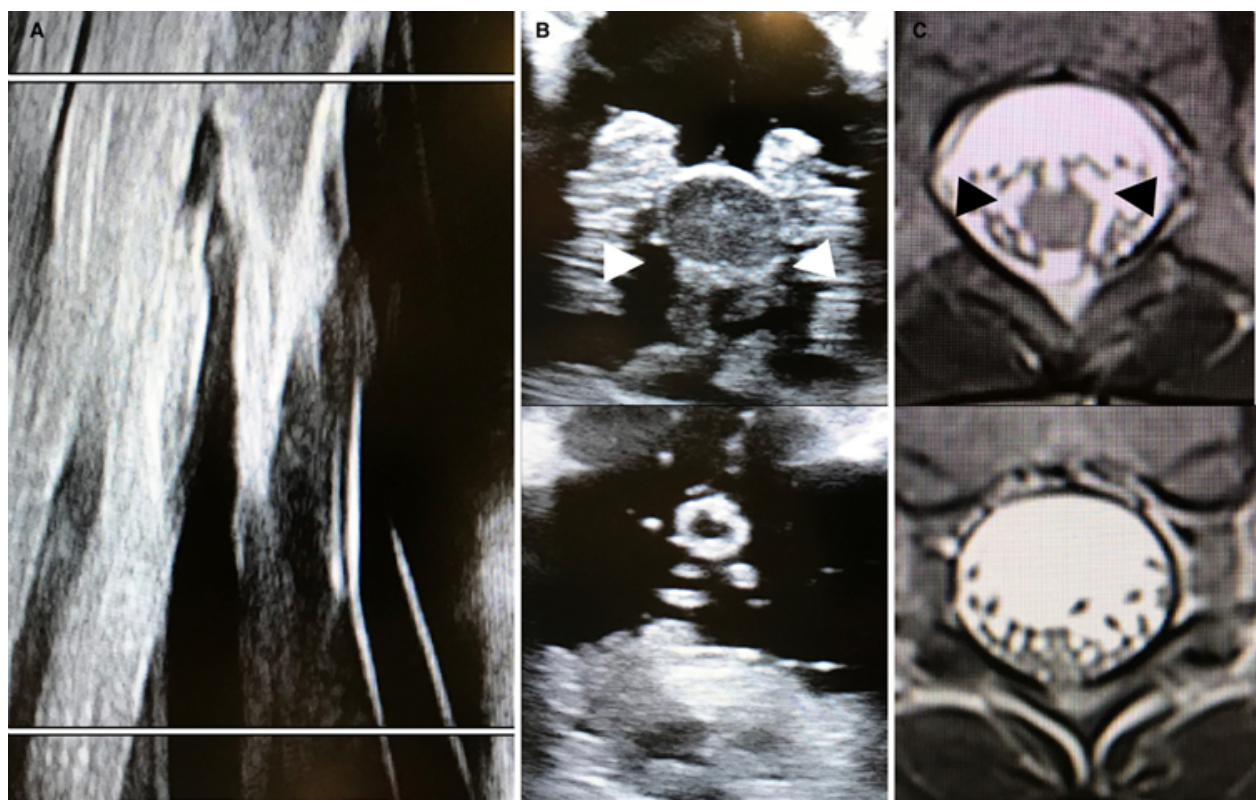

FIG. 2. Ultrasound and MR images of the CSF "cleft" used to distinguish dorsal and ventral roots. A: Sagittal ultrasound view of the conus medullaris below bony exposure. B: Axial ultrasound view at the conus showing the CSF cleft used to distinguish dorsal and ventral roots (arrowheads [upper]) and below the conus (lower), where the cleft can no longer be appreciated. C: MRI correlation of the CSF cleft as seen on ultrasonic views (upper image at the conus and lower image below). Figure is available in color online only.

their experience of limiting the lumbar exposure. ${ }^{16}$ Following induction of general anesthesia, patients are positioned prone on gel bolsters in Trendelenburg angulation to encourage rostral pooling of cerebrospinal fluid (CSF). In children younger than 10 years of age, ultrasound images of the conus and cauda equina are obtained to guide the approach. In older children, where this would not be possible, the L1 spinous process is localized using X-ray imaging and marked with infiltration of indigo carmine dye.

Following a limited midline lumbar incision over the interspinous space overlying the conus, the interspinous ligament and ligamentum flavum are excised to permit further ultrasonic views. Typically, two levels are examined to localize the conus and cauda equina. A laminectomy over the index level is performed using a craniotome to minimize facet joint disruption, whereupon the ultrasound is reemployed to reassess the conus' position to determine whether additional caudal laminectomies are necessary to expose at least $5 \mathrm{~mm}$ of the caudal conus. This allows safe separation of the dorsal and ventral roots.

A linear dural incision is made and the operating microscope is then introduced. The operating table may be tilted away from the surgeon to permit dissection of the contralateral nerve roots. The arachnoid is divided and the conus and filum terminale are visualized. The L2 nerve roots are next identified at their respective foramina. The dorsal and ventral roots are separated and traced back to the conus in order to appreciate the cleft that defines ventral and dorsal sections (Fig. 2). Following medial displacement of the L2 root and neighboring dorsal roots, the ventral roots are covered with a cottonoid. Next the surgeon is advised to identify the S2 root and lower sacral roots (S3-5). The lower sacral nerves characteristically have little space between them and are left intact. A Silastic sheet is positioned under the dorsal L2-S2 nerve roots to gently separate them from the ventral roots as the procedure proceeds.

Once the dorsal roots are spread on the Silastic sheet, EMG testing on each root takes place to establish an innervation pattern using the hooks of the rhizotomy probes. Threshold voltages are determined via recordings from the lower-limb musculature. The root is then dissected into 3-5 rootlets or fascicles of equal size using a Scheer needle and stimulated with constant square-wave pulses of $0.1 \mathrm{msec}$ at a rate of $0.5 \mathrm{~Hz}$. An increasing stimulus is applied until a reflex response is visualized from the ipsilateral muscles. When a reflex threshold is determined, the rootlet is then subjected to a train of a $50-\mathrm{Hz}$ tetanic stimulation for 1 second and the resulting reflex graded.

Park and Johnston ${ }^{16}$ based their decision to divide a given rootlet on the number of rootlets producing sustained responses at that level and their response intensity, as described by Phillips and Park. ${ }^{19}$ Rootlets producing a significant reflex response (typically $3+$ or $4+$ ) undergo division. At least one rootlet is left intact in order to preserve sensation. Deafferented roots are sequentially placed below the Silastic sheet to separate them from the untested bundle. The authors report sectioning $60 \%-65 \%$ of the examined nerve roots. Half of the L1 root is routinely divided without EMG testing as it was deemed unreliable for this level. The dura mater is closed with a 4-0 monofilament nylon. An intradural injection of clonidine and morphine is applied, and Gelfoam is left over the laminectomy defect before a layered wound closure is performed. Since their 
initial publication, the group has also described the addition of a postoperative epidural catheter to improve patient analgesia..$^{14}$

\section{Bales et al.}

In 2016, Bales et al. ${ }^{1}$ described a modification of Park's technique that selectively analyzed each individual nerve root with EMG to separate dorsal and ventral nerve roots through comparison of stimulus responses. They argued that the anatomical variation present at the level of the conus can make Park's anatomical approach to identifying the dorsal roots particularly challenging, and therefore they advocated for the use of electrophysiology to dichotomize the rootlets.

Preoperative MRI is performed to determine the level of the conus. After induction of general anesthesia, the patient is placed in the prone position and the laminectomy is planned for one vertebral level below the conus, typically at L2. An intraoperative radiograph is taken to verify the location of the appropriate level, which is then marked at the level of the skin. A single-level laminectomy is performed, and intraoperative ultrasound is used to visualize the nerve roots and ensure the exposure is below the level of the conus. Care is taken to remain medial to the facets to minimize the risk of postlaminectomy spinal deformity. The dura and arachnoid are opened, and a Silastic sheet cut to a width of 3-4 $\mathrm{mm}$ is placed ventrally around all the roots of the cauda equina.

Direct stimulation of the nerve rootlets is achieved with bipolar stimulation using rhizotomy probes. The initial goal is to differentiate the ventral and dorsal nerve rootlets by recording motor thresholds. Motor responses following direct stimulation of ventral (motor) rootlets are typically achieved at a range of less than $0.4-0.5 \mathrm{~mA}$ and most commonly stimulate at $0.1 \mathrm{~mA}$. By comparison, dorsal (sensory) rootlets have thresholds greater than $0.5 \mathrm{~mA}$ and most commonly stimulate above $1.0 \mathrm{~mA}$. Rootlets that stimulate at low thresholds (typically $<0.4 \mathrm{~mA}$ ) are excluded as ventral (motor) rootlets and are tucked behind the Silastic dam. Rootlets that elicited an anal sphincter response are also preserved. Rootlets that stimulate at the established threshold for sensory rootlets are further stimulated with a 1-second train of $50-\mathrm{Hz}$ tetanic stimulation.

Dorsal rootlet responses are graded based on Park's criteria, as previously described..$^{16}$ If the response is markedly abnormal, $75 \%-90 \%$ of the rootlet is cut. If slightly abnormal, $50 \%$ of the rootlet is cut. If the response to tetanic stimulation is normal but the rootlet elicits a response only in affected muscle groups, $50 \%$ of the rootlet is incised. Once all the rootlets have been stimulated in this fashion, the number of rootlets that are incised is reviewed to ensure that there is adequate representation of the affected muscle groups.

\section{Sindou et al.}

In 2015, Sindou and Georgoulis ${ }^{22}$ described the keyhole interlaminar dorsal rhizotomy technique in an attempt to overcome the potential disadvantages of multilevel laminectomy. The goals were to achieve anatomical accuracy of the ventral and dorsal nerve roots, functional selectivity through electrophysiology, and reduction of the risks of spinal instability.

Anatomical accuracy is achieved by surgically accessing roots where both their ventral and dorsal components are clearly separated at the exit to/entry from their foraminal sheath. This anatomical localization is then followed by functional verification of the dorsal root by electrical stimulation and subsequent interruption of the dorsal root/ rootlets likely to participate in spasticity. According to the authors, the risk of spinal instability is minimized by maximal preservation of the bony and posterior ligamentous structures through an interlaminar spinal approach.

Preoperatively, afferents from the most affected muscles are identified based on anatomical knowledge. These specific dorsal nerve roots are then targeted through 2 or 3 interlaminar spaces. For example, the transiting L 3 and L4 dorsal roots could be accessed through an L2 -3 interlaminar keyhole. The patient is positioned prone, and a midline lumbar incision is performed according to the topography of the predetermined interlaminar spaces. An intraoperative radiograph is used to confirm the operative levels. The muscles are dissected, while leaving the spinous processes and interspinous ligaments intact. At the selected interlaminar spaces, the ligamentum flavum is removed and the space is expanded with rongeurs. The lower two-thirds of the upper lamina and the upper two-thirds of the lower lamina are removed in the midline underneath the interspinous ligaments.

A 2-cm midline opening is made in the dura and arachnoid. The microscope is then employed, and an oblique trajectory, on the order of $45^{\circ}$, is used to access the contralateral roots by passing underneath the preserved interspinous ligaments. Through this approach, Sindou et al., ${ }^{23}$ have found that the ventral and dorsal components of the nerve root are identified constantly at the exit to/entry from their corresponding dural sheath. Two roots can be accessed on each side, one upward and one downward. At this point, the posteriorly located dorsal root with its 4-5 rootlets are tested with electrophysiology, as previously described, and subsequently sectioned if selected based on the Phillips and Park criteria. ${ }^{19}$

\section{Funk and Haberl}

In 2016, Funk and Haberl ${ }^{8}$ published a paper describing a single-level laminoplasty approach. Their aim was again to minimize instability of the spine, and by extension reduce the incidence of late scoliosis.

Their technique begins with preoperative MRI to locate the level of the conus medullaris. The patient is placed prone, and a laminectomy utilizing a craniotome drill at the level of the conus is used to provide interlaminar access. The authors then describe the use of long-blade Ruskin bone-splitting forceps to make oblique cuts in the spinous processes above and below the level where the laminae are dissected. With these cuts, a midline complex is disconnected from the rest of the spine and stored in a damp cloth. This complex consists of the spinous process of the MRI-defined level, the adjoining medial lamina, the adjacent superior and inferior spinous process segments attached through the intervening posterior ligaments.

A midline dural incision follows, and the L1-S2 dorsal 
sensory roots are separated and placed in a Silastic sheet. For the L1 rootlet, $50 \%$ of the sensory rootlets are cut without EMG. From L2 to S1, at each given level, roots are separated into anywhere from 4 to 8 rootlets. According to EMG evaluation using the Phillips and Park grading scale, $50 \%-60 \%$ of the rootlets are cut. ${ }^{19}$ The S2 root is divided into 2 parts, the bulbocavernous reflex is stimulated, and the fascicle showing the least pudendal nerve activity is severed.

Following the SDR, the dura is closed tightly, and the aforementioned midline complex is replated to the spine, across the intact spinous process and dissected lamina. This is done using multihole miniplates. The superior and inferior obliquely cut spinous processes are fixed to their respective ends using single sutures. In younger children, this suturing is done once through the bony spinous process. In older children, the stitch is placed twice around the spinous process fragments through the interspinous ligaments. Muscle and fascia are closed with sutures running through the interspinous and supraspinous ligaments.

\section{The $2 \times 3$ Exposure Technique}

Patients are initially assessed in a multidisciplinary clinic. Candidates are typically 4-8 years old, with ambulatory spastic diplegic CP. Clinical examinations and EMG recordings from the L1-S1 muscle groups are used to form a preoperative rhizotomy plan. This plan is made in consensus with the neurosurgical and physiotherapy teams. The anticipated amount of dorsal root transection at each level is generally on the order of $50 \%-70 \%$.

A preoperative MR image of the spine is used to identify the level of the conus so as to inform the ideal location of a 2-level laminoplasty aimed at unroofing the L2-S1 nerve roots. With the patient in the prone position, intraoperative fluoroscopy is used to identify the target levels for the laminoplasty, and these levels are demarcated on the skin. A clear drape is placed inferiorly and tented over a curtain to allow physiotherapists access to the lower extremities.

A midline dissection is performed until the supraspinous ligament overlying the planned laminoplasty site is identified. Bilateral subperiosteal dissections are then performed while sparing this ligament. A 2-level laminoplasty respecting the medial facet is then performed (Fig. 1). Inferiorly, the supraspinous ligament, interspinous ligament, and ligamentum flavum are divided. The spinous processes and posterior ligament complex above the target site are preserved and reflected superiorly. The ultrasound probe is used to confirm the level of the conus, as well as to appreciate the cleft between dorsal and ventral roots visible only at this level (Fig. 2). This allows us to identify the optimal location for the midline dural opening. The dural leaflets are then tacked dorsolaterally to fascia to maximize intradural visualization.

The method is described herein as a $2 \times 3$ exposure because two nerve roots (most commonly L2 and L3) can be visualized at the dural exit site, and 3 nerve roots (most commonly L4, L5, and S1) are identified in the midline. L2 is readily identified beneath the $\mathrm{L} 2$ pedicle, and anatomically, the dorsal and ventral roots are separated and L2 is sectioned. A Silastic sheet is then placed in the CSF cleft at the conus separating the dorsal and ventral roots from

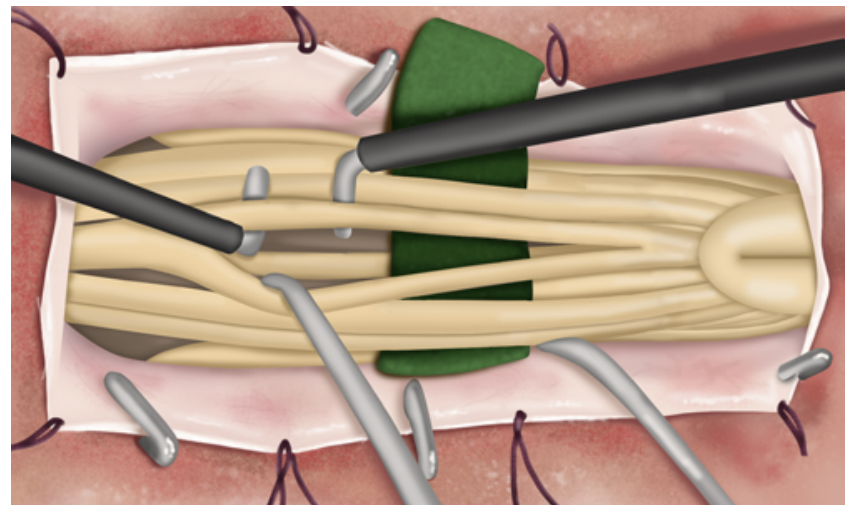

FIG. 3. Schematic representation of rootlet division. As shown, a Silastic sheet is placed between the dorsal and ventral nerve roots. The dorsal (sensory) nerve roots are then divided into individual rootlets using microdissectors. Stimulation of each individual rootlet then proceeds as described. Copyright Nebras Warsi. Published with permission.

L3 to S1 (Fig. 3). The L3 nerve root is followed inferiorly toward its lateral exit site in the dura, which can be visualized by sharply angling the operating microscope. This provides final anatomical confirmation of the separation of motor and sensory roots. From lateral to medial, L4 to S1 are stimulated and sectioned systematically thereafter. We repeat the procedure on the contralateral side, and finally, when indicated, L1 may be sectioned by sharply angling the microscope superiorly. If indicated, the exposure also provides opportunity to selectively section the S2 dorsal rootlets, as previously described, although this is not routinely performed for all patients.

Our stimulation protocol uses a bipolar probe with a $100-\mu \mathrm{sec}$ pulse width, which is delivered at $2.1 \mathrm{~Hz}$ to the left and right L2-S1 nerve roots in order to obtain both sensory and motor stimulation intensity thresholds. At each level, both dorsal sensory and ventral motor roots are identified and separated with a Silastic sheet. Rootlets within the sensory roots are dissected apart using microdissectors. The S2-4 nerve roots are confirmed via stimulation and are spared.

Tetanic stimulation at sensory thresholds is then applied to separate rootlets at a frequency of $50 \mathrm{~Hz}$ for $1 \mathrm{sec}-$ ond. We grade responses to stimulation of rootlets using the Phillips and Park classification system..${ }^{19}$ Rootlets with the most abnormal responses are transected. The number of rootlets transected at a given level is based on the preoperative rhizotomy plan described above. This process is continued systematically to bilateral L2-S1 nerve roots. Evoked potentials are then used to confirm the functional integrity of the ventral roots prior to closure.

The dura is closed in a watertight fashion, and the laminoplasty complex is reflected back into position and fixed to native bone using miniplates. The remaining closure process proceeds in standard multilayer fashion for the lumbar spine.

\section{Discussion}

As interest in SDR continues to grow, there is a need to 
evaluate and compare the various surgical nuances of this procedure. A variety of techniques have been described, which vary with regard to the extent of bony exposure, identification of dorsal and ventral nerve roots, and selection of appropriate rootlets for sectioning (Table 1).

Peacock et al. ${ }^{17}$ have described the largest bony exposure, which may be associated with an increased incidence of spinal deformity. ${ }^{10}$ Alternatively, 1- and 2-level procedures come at the cost of easy anatomical identification of individual nerve roots. To circumvent this problem, the use of extended EMG recordings increases the specificity of nerve root identification. ${ }^{11}$ The technique described by Bales et al. ${ }^{1}$ has considerable overlap with that initially described by Park and Johnston. ${ }^{16}$ However, a key difference is that Bales et al. make their opening below the conus and identify nerve roots using EMG, which is an entirely different process from the anatomical identification described by Park and Johnston. Sindou and colleagues ${ }^{22,23}$ described a keyhole interlaminar approach, whereas Funk and Haberl used a single-level laminoplasty. Our 2-level laminoplasty potentially mitigates the risk of multilevel laminectomy with several advantages over a single-level approach. Cranially, the anatomy of the conus, and the CSF cleft between dorsal and ventral roots is preserved (Fig. 2), facilitating separation of the ventral and dorsal roots. Caudally, two levels of exiting nerves (typically L2 and L3) can be identified at the dural exit site, providing confirmation of the separation between motor and sensory roots. Distal to the conus, the sensory roots are best appreciated and can be traced backward toward the conus. Furthermore, with regard to bony exposure, there is evidence to suggest that laminoplasty confers increased biomechanical stability to the spine compared with laminectomy, although the exact extent of this advantage is unclear. $^{10,25}$

With regard to postoperative spinal deformity, there is a growing body of literature to support the long-term risks of this complication with multilevel bony exposures. ${ }^{3,4,9,20,24,27}$ The incidence of postoperative spinal deformity ranges from approximately $12 \%$ to greater than $35 \%$ in the literature ${ }^{3,4,9,20,24,27}$ Interestingly, even without surgery Saito et al. estimated the rate of spinal deformity in $\mathrm{CP}$ to be $68 \%$, especially scoliosis, with large multilevel exposures thought to increase this risk. ${ }^{21}$ Unfortunately, at present, no comparative studies exist that have assessed whether approaches such as the keyhole interlaminar approach and laminotomy techniques offer a significant advantage in this regard.

Identification of appropriate nerve roots is another challenge in SDR as the procedure by which candidate nerve roots are targeted can vary widely based on the operative approach. For example, many of the procedures described require tracing back each root with an operative microscope and identifying the cleft at the conus to separate dorsal and ventral roots. The benefits of these conus-level approaches are that they allow a more limited bony exposure. In our experience and in the literature, this procedure has been successful but does require thorough knowledge of the anatomy at the level of the conus. Similarly, for the keyhole interlaminar approach, intimate operative experience with lumbar laminoforaminotomy techniques is criti- cal for adequate exposure and identification of relevant nerve roots. In this regard, Peacock and colleagues' initial approach is simplest, ${ }^{17}$ followed by Bales et al.'s dichotomizations of nerve roots using EMG. ${ }^{1}$

Beyond identification of nerve roots, the extent to which each root should be transected is unclear. There is evidence to suggest a direct relationship between the percentage of dorsal root transected and postoperative functional improvement. ${ }^{12}$ At our institution, we employ preoperative assessments to determine the amount to transect at each level; however, this is not widely accepted. Intraoperatively, we only transect rootlets with the most abnormal responses, and our target is on the order of $50 \%-70 \%$ per level. This is in keeping with the technique described by Funk and Haberl. However, it is not clear whether it is more important to transect simply a larger percentage of the dorsal root or simply a larger percentage of the subset of abnormal rootlets.

Given that no single approach is clearly superior, the technique used will depend on individual surgeon preference and comfort with the variable interrelationship between anatomy and neurophysiology in this patient population.

\section{Conclusions}

A number of questions remain to be answered as they pertain to these different operative approaches to SDR. One critical avenue of further study will be a comparison of each of these operative techniques vis-à-vis the outcomes and potential complications. Similarly, it would be important to evaluate these factors among different centers and surgeons, as significant heterogeneity has been previously reported. For example, Park's group, reported only a single CSF leak requiring operative repair in their series of 1500 patients and no spinal deformity requiring operation, while other articles put the incidence of significant spinal deformity in the $10 \%$ range. $3,4,9,16,20,24,27$ The value of adjuncts, including intraoperative neuromonitoring, should also be the subject of future research.

\section{References}

1. Bales J, Apkon S, Osorio M, Kinney G, Robison RA, Hooper $\mathrm{E}$, et al: Infra-conus single-level laminectomy for selective dorsal rhizotomy: technical advance. Pediatr Neurosurg 51:284-291, 2016

2. Canty MJ, Breitbart S, Siegel L, Fehlings D, Milo-Manson $\mathrm{G}$, Alotaibi NM, et al: The role of social media in selective dorsal rhizotomy for children: information sharing and social support. Childs Nerv Syst 35:2179-2185, 2019

3. Cobb MA, Boop FA: Replacement laminoplasty in selective dorsal rhizotomy: possible protection against the development of musculoskeletal pain. Pediatr Neurosurg 21:237242,1994

4. Crawford K, Karol LA, Herring JA: Severe lumbar lordosis after dorsal rhizotomy. J Pediatr Orthop 16:336-339, 1996

5. Enslin JMN, Langerak NG, Fieggen AG: The evolution of selective dorsal rhizotomy for the management of spasticity. Neurotherapeutics 16:3-8, 2019

6. Fasano VA, Broggi G, Zeme S: Intraoperative electrical stimulation for functional posterior rhizotomy. Scand J Rehabil Med Suppl 17:149-154, 1988

7. Fasano VA, Broggi G, Zeme S, Lo Russo G, Sguazzi A: 
Long-term results of posterior functional rhizotomy. Acta Neurochir Suppl (Wien) 30:435-439, 1980

8. Funk JF, Haberl H: Monosegmental laminoplasty for selective dorsal rhizotomy-operative technique and influence on the development of scoliosis in ambulatory children with cerebral palsy. Childs Nerv Syst 32:819-825, 2016

9. Golan JD, Hall JA, O'Gorman G, Poulin C, Benaroch TE, Cantin MA, et al: Spinal deformities following selective dorsal rhizotomy. J Neurosurg 106 (6 Suppl):441-449, 2007

10. Johnson MB, Goldstein L, Thomas SS, Piatt J, Aiona M, Sussman M: Spinal deformity after selective dorsal rhizotomy in ambulatory patients with cerebral palsy. J Pediatr Orthop 24:529-536, 2004

11. Legatt AD, Schroeder CE, Gill B, Goodrich JT: Electrical stimulation and multichannel EMG recording for identification of functional neural tissue during cauda equina surgery. Childs Nerv Syst 8:185-189, 1992

12. McLaughlin J, Bjornson K, Temkin N, Steinbok P, Wright V, Reiner A, et al: Selective dorsal rhizotomy: meta-analysis of three randomized controlled trials. Dev Med Child Neurol 44:17-25, 2002

13. Moher D, Liberati A, Tetzlaff J, Altman DG: Preferred reporting items for systematic reviews and meta-analyses: the PRISMA statement. PLoS Med 6:e1000097, 2009

14. Moore RP, Wester T, Sunder R, Schrock C, Park TS: Perioperative pain management in children with cerebral palsy: comparative efficacy of epidural vs systemic analgesia protocols. Paediatr Anaesth 23:720-725, 2013

15. National Institute for Health and Care Excellence: Final Report: Selective Dorsal Rhizotomy (SDR). London: Centre for Health Technology Evaluation Observational Data Unit, 2018 (https://www.england.nhs.uk/commissioning/ wp-content/uploads/sites/12/2019/04/SDR-CtE-NICEEvaluation-Report.pdf) [Accessed December 20, 2019]

16. Park TS, Johnston JM: Surgical techniques of selective dorsal rhizotomy for spastic cerebral palsy. Technical note. Neurosurg Focus 21(2):e7, 2006

17. Peacock WJ, Arens LJ, Berman B: Cerebral palsy spasticity. Selective posterior rhizotomy. Pediatr Neurosci 13:61-66, 1987

18. Peacock WJ, Eastman RW: The neurosurgical management of spasticity. S Afr Med J 60:849-850, 1981

19. Phillips LH, Park TS: Electrophysiology studies of selective posterior rhizotomy patients, in Park TS, Phillips LH, Peacock WJ (eds): Management of Spasticity in Cerebral Palsy and Spinal Cord Injury. Neurosurgery. State of the Art Reviews. Philadelphia: Hanley \& Belfus, 1989, pp 459-469

20. Ravindra VM, Christensen MT, Onwuzulike K, Smith JT, Halvorson K, Brockmeyer DL, et al: Risk factors for progressive neuromuscular scoliosis requiring posterior spinal fusion after selective dorsal rhizotomy. J Neurosurg Pediatr 20:456-463, 2017

21. Saito N, Ebara S, Ohotsuka K, Kumeta H, Takaoka K: Natural history of scoliosis in spastic cerebral palsy. Lancet 351:1687-1692, 1998
22. Sindou M, Georgoulis G: Keyhole interlaminar dorsal rhizotomy for spastic diplegia in cerebral palsy. Acta Neurochir (Wien) 157:1187-1196, 2015

23. Sindou M, Georgoulis G, Mertens P: History of neurosurgical treatment for spasticity, in Neurosurgery for Spasticity. A Practical Guide for Treating Children and Adults. Vienna: Springer, 2014

24. Steinbok P, Hicdonmez T, Sawatzky B, Beauchamp R, Wickenheiser D: Spinal deformities after selective dorsal rhizotomy for spastic cerebral palsy. J Neurosurg 102 (4 Suppl):363-373, 2005

25. Subramaniam V, Chamberlain RH, Theodore N, Baek S, Safavi-Abbasi S, Senoğlu M, et al: Biomechanical effects of laminoplasty versus laminectomy: stenosis and stability. Spine (Phila Pa 1976) 34:E573-E578, 2009

26. Summers J, Coker B, Eddy S, Elstad M, Bunce C, Bourmpaki $\mathrm{E}$, et al: Selective dorsal rhizotomy in ambulant children with cerebral palsy: an observational cohort study. Lancet Child Adolesc Health 3:455-462, 2019

27. Turi M, Kalen V: The risk of spinal deformity after selective dorsal rhizotomy. J Pediatr Orthop 20:104-107, 2000

\section{Disclosures}

The authors report no conflict of interest concerning the materials or methods used in this study or the findings specified in this paper.

\section{Author Contributions}

Conception and design: Ibrahim, Warsi, Dewan. Acquisition of data: Warsi, Tailor, Coulter, Shakil. Analysis and interpretation of data: Ibrahim, Warsi, Tailor, Coulter, Shakil, Breitbart, Dewan. Drafting the article: Warsi, Tailor, Coulter, Shakil, Workewych, Haldenby. Critically revising the article: all authors. Reviewed submitted version of manuscript: all authors. Approved the final version of the manuscript on behalf of all authors: Ibrahim. Statistical analysis: Administrative/technical/material support: Haldenby, Breitbart, Strantzas, Vandenberk. Study supervision: Ibrahim, Dewan. Illustrations: Workewych.

\section{Supplemental Information \\ Online-Only Content}

Supplemental material is available with the online version of the article.

Supplementary Figs. 1 \& 2. https://thejns.org/doi/suppl/ 10.3171/2019.12.PEDS19629.

\section{Correspondence}

George M. Ibrahim: Hospital for Sick Children, Toronto, ON, Canada. george.ibrahim@sickkids.ca. 